ГРИБИН Николай Петрович - доктор юридических наук, профессор; директор Центра европейских исследований Института международных исследований Московского государственного института международных отношений (университет) МИД России (119454, Россия, г. Москва, nр-кт Вернадского, 76; n.gordin40@gтаil.com)

ЯКУТОВА Ульяна Вячеславовна - лаборант-исследователь Центра европейских исследований Института международных исследований Московского государственного института международных отношений (университет) МИД России (119454, Россия, г. Москва, пр-кт Вернадского, 76; uliana.postnikova@gmail.com)

\title{
ОСОБЕННОСТИ ФОРМИРОВАНИЯ СИСТЕМЫ НАЦИОНАЛЬНОЙ БЕЗОПАСНОСТИ МАЛЫХ ПРИБАЛТИЙСКИХ ГОСУДАРСТВ
}

Аннотация. В статье рассматриваются особенности процесса концептуализации национальной безопасности Латвии, Литвы и Эстонии после обретения ими независимости в 1991 г. Авторы демонстрируют эволюцию подходов прибалтийских государств к национальной безопасности - от соблюдения нейтралитета и обеспечения максимальной независимости к признанию НАТО краеугольным камнем национальной безопасности и использованию так называемой российской угрозы в качестве инструмента консолидации общества. Особое внимание уделяется анализу ключевых документов в сфере национальной безопасности, выявлению общих тенденций и отличий в определении и решении проблем национальной безопасности.

Ключевые слова: национальная безопасность, стратегия национальной безопасности, концепция национальной безопасности, кибербезопасность, энергетическая безопасность, национальная идентичность, прибалтийские государства

$\Pi^{2}$ осле выхода в 1991 г. из состава Советского Союза три малых прибалтийских республики - Латвия, Литва и Эстония - в процессе утверждения своего суверенитета были вынуждены самостоятельно решать сложнейшие проблемы конституционного порядка, характерные для любого государства, ставшего на путь независимого развития. Важное место среди этих проблем заняла тема формирования системы национальной безопасности, при том что само содержание безопасности в конце XX и начале XXI в. довольно неожиданно для самих этих государств после эйфории обретения независимости наполнилось новыми вызовами и угрозами. Небольшие по размеру территории этих государств, ограниченные природные и человеческие ресурсы, особенности этнического состава населения, геополитическое расположение, исторические и институциональные аспекты развития, кардинальная структурная переориентация национальных экономик и многое другое в значительной степени предопределило концептуальные подходы национальных элит этих «младоевропейцев» к формированию политики в области безопасности.

Этот процесс проходил с большими трудностями, вызванными прежде всего отсутствием в политических и общественных кругах единства в понимании статуса малых прибалтийских государств на политической карте Европы, а также в определении путей решения многочисленных экономических и социально-политических проблем, связанных с выходом из Советского Союза. Негативное влияние на процесс формирования суверенной политики в области безопасности оказывал дефицит квалифицированных кадров - политологов, юристов-международников, специалистов в области национальной безопасности и специальных служб (разведка, контрразведка, полиция, таможенная служба и т.д.). 
Определенные проблемы при подготовке концептуальных документов в области национальной безопасности были также связаны с новыми для «младоевропейцев» угрозами и вызовами (международный терроризм, организованная преступность, распространение оружия массового поражения и т.д.), борьбу с которыми прибалтийские государства, находясь в составе СССР, «делегировали» союзным (федеральным) властям. Особое место в перечне этих угроз заняло состояние национальной экономики, процесс адаптации которой к требованиям Европейского союза оказался гораздо более сложным, чем это представлялось национальным прибалтийским элитам до вступления в 2004 г. в ЕС.

Одной из наиболее острых тем в начальный период формирования подходов к проблемам национальной безопасности, вокруг которой сосредоточилось стратегическое осмысление проблем безопасности, стали исторические «драматические» события 1940 г., когда прибалтийские государства были «вмонтированы» в состав СССР. Задача избежать, не допустить повторения подобной ситуации, «уберечь» свою страну от этого превалировала во всех дискуссиях, связанных с обеспечением безопасности. Причем на начальном этапе этих обсуждений, как отмечают прибалтийские исследователи, среди части элит была популярна идея нейтрального статуса республик. Так, в 1989 г., т.е. еще до обретения Латвией, Литвой и Эстонией независимости, лидер эстонской националистической оппозиции Туннэ Келам заявил, что «эстонцы смогут выжить только в нейтральном, независимом государстве вне военных блоков» [Apprenticeship... 2013: 21]. Затем тезис о перспективах развития страны как независимого, нейтрального государства повторяется в первом проекте Концепции безопасности Республики Эстонии, разработанной в 1993 г.

Схожую с эстонскими соседями позицию о нейтральном статусе своей страны в начале 1990-х гг. выразили разработчики проектов концепций национальной безопасности Латвии и Литвы. Роль Латвии в первом проекте концепции национальной безопасности определялась в качестве своеобразного моста между Востоком и Западом, что, по их мнению, способствовало бы обеспечению безопасности страны. В свою очередь, главной целью политики безопасности Литвы, согласно проекту концепции национальной безопасности, подготовленному в 1992 г. группой ученых из Института философии, социологии и права Литовской академии наук, стало «обеспечение максимальной независимости как от Востока, так и от Запада» [Miniotaite 1999: 15]. Авторы документа боялись, что «вестернизация» может обернуться размыванием национальной идентичности и утратой национальной культуры и ценностей, поэтому интеграционные процессы за исключением таковых с соседскими скандинавскими и балтийскими странами рассматривались как угрожающие национальной безопасности республики. Однако уже в мае 1993 г. из «европейской речи» президента Литвы А. Бразаускаса становится понятным, что литовское руководство сделало свой окончательный выбор в пользу концепции коллективной безопасности: «...в то время мы отдалялись от понимания политики нейтралитета как наилучшего выхода для Литвы. Мы искали новые гарантии безопасности, в то время когда в стране еще находилась Российская армия. Поэтому я и поддержал идею "НАТО-бис" - обсуждаемую возможность создания в Средней Европе новой обеспечивающей безопасность организации, говорил о вовлечении государств СНГ в зону безопасности. Именно с этой целью через несколько лет была начата Программа партнерства во имя мира» [Бразаускас 2002: 243].

Таким образом, концепция «максимальной независимости» и нейтралитета как временная мера утратила свою актуальность и в конечном итоге уступила 
место концепции «прифронтовых государств» (front-line states) на восточном фланге НАТО [Смирнов 2017: 58]. Вступление в НАТО виделось балтийскими странами естественным продолжением борьбы за свою независимость от восточного соседа. Кроме того, Латвия, Литва и Эстония воспринимали НАТО «не просто как военный альянс с гарантиями безопасности согласно статье 5, но как символ цивилизованного мира, в котором странам Балтии следует найти надлежащее место» [Urbelis 2003: 3].

Заметное влияние на формирование прибалтийскими государствами концептуальных подходов к проблемам своей безопасности оказали идеи глубокого и всеобъемлющего сотрудничества между прибалтийскими государствами, укрепления связей с государствами Центральной и Северной Европы (Швеция, Финляндия, Норвегия, Дания), а также необходимости «институционализации» гарантий своей безопасности как со стороны западных государств, так и со стороны России.

К середине 1990-х гг. в прибалтийских государствах начал формироваться консенсус в отношении основных принципов, определяющих состояние и перспективы обеспечения их национальной безопасности.

В 1996 г. в Эстонии был одобрен документ под названием «Основные направления оборонной политики Эстонии» (Guidelines of the National Defense Policy of Estonia). Эстонские политические деятели исходили из того, что главная угроза безопасности Эстонии - военная. В этой связи национальной обороне как главному способу обеспечения национальной безопасности отдавалось первостепенное значение. В тот период авторам документа не удалось выстроить целостную, всеобъемлющую концепцию национальной безопасности. Фактически главным достижением этого документа стала констатация необходимости для Эстонии иметь свои вооруженные силы [Apprenticeship... 2013: 22].

Аналогичный документ был подготовлен в Литве. В Базовых принципах национальной безопасности (Basics of National Security) литовские эксперты предприняли попытку определить основные принципы и объекты системы национальной безопасности республики, к которым отнесли «права человека и гражданина, фундаментальные свободы и личную безопасность; ценности, которыми дорожит народ, его права и условия для свободного развития; независимость государства; конституционный строй; целостность территории; природное и культурное наследие» [Möller 2007: 151]. В то же время такой ключевой аспект системы национальной безопасности, как национальные интересы, остался за скобками этого документа.

Дальше всех в теоретическом, политическом и практическом осмыслении проблем национальной безопасности продвинулась в тот период Латвия. Итогом политических дискуссий стало принятие Концепции безопасности Республики Латвия (Security Concept of the Republic of Latvia, 1997). Особое внимание в концепции уделялось необходимости сотрудничества балтийских стран как «одному из условий и способов интеграции в европейские и трансатлантические структуры, а также гарантии политической и экономической автономии» [Almost... 2003: 272]. Кроме того, политика безопасности Латвии исходила из представления, что угроза одному из балтийских государств является угрозой для всех. Вместе с тем, несмотря на успехи в теоретизировании, Латвия столкнулась со сложностями при попытках претворить Концепцию в жизнь. Серьезные разногласия между политической и военной верхушкой республики, в частности по вопросу оценок угроз в военной сфере и реальных возможностей их нейтрализации, не позволили выработать эффективный план по развитию вооруженных сил [Apprenticeship... 2013: 22]. 
Вступление в 2004 г. прибалтийских республик в Североатлантический альянс, а затем и в Европейский союз, с одной стороны, привело к унифицированию их подходов к своей безопасности, а с другой - обострило традиционную болезненную для балтийских республик тему своей национальной идентичности. И хотя Латвия, Эстония и Литва стремились оставаться в целом национальными по своему характеру, их концептуальные документы в сфере безопасности того периода приобрели более глубокое «трансатлантическое» содержание, что стало очевидным следствием совместной работы прибалтийских специалистов с экспертами в области национальной безопасности ведущих стран НАТО, и прежде всего Соединенных Штатов, система обеспечения национальной безопасности которых, включающая целый ряд концептуальных документов, стала для «молодых» и «малых» государств НАТО эталоном в этой области.

Вместе с тем по мере формирования в прибалтийских государствах общенатовских подходов к обеспечению безопасности в сознании политических элит укреплялась идея, что любая документально-правовая система обеспечения безопасности должна представлять собой не только базу, на которой парламенты и правительства будут принимать решения, отражающие национальные интересы этих государств, но и некую «декларацию намерений» для мирового сообщества, прежде всего для партнеров по НАТО и ЕС.

Несмотря на то что в концептуальных документах, направленных на обеспечение своей безопасности, государства Балтии декларировали стремление укреплять и развивать в первую очередь национальный аспект военной безопасности, со времени вступления в НАТО военная составляющая безопасности стала для прибалтийских государств, с одной стороны, одним из основных элементов интеграции в Североатлантический союз, с другой - способом заявить о себе в качестве субъекта международного права участием в различных миротворческих операциях, проводимых под эгидой ООН и НАТО. В пропорциональном отношении к численности населения Латвия, Литва и Эстония стали главными «поставщиками» военного контингента для участия в операциях в Афганистане и Ираке, зарекомендовав себя как надежные союзники.

Одной из важнейших и достаточно болезненных оставалась тема получения гарантий всеобъемлющей безопасности как со стороны ведущих государств Запада, так и со стороны России. В этом контексте концепция «ближнего зарубежья», выдвинутая российскими стратегами, вызвала у балтийских государств откровенное неприятие и опасение, поскольку, по их мнению, в этой концепции содержалось завуалированное намерение России втянуть прибалтийские государства в орбиту своих геополитических интересов.

К 2010-м гг. окончательно сложилось понимание подходов к проблеме обеспечения национальной безопасности. Для Латвии, Литвы и Эстонии характерно встраивание в систему международной безопасности и стремление делегировать решение проблем другим, более крупным государствам и международным организациям. Главным гарантом и краеугольным камнем своей безопасности страны Балтии считают НАТО и при формировании своей оборонной политики ориентируются на США, в то время как сотрудничество с ЕС рассматривается в качестве основного способа улучшить свое экономическое положение. В этой связи «особенность интеграции стран Балтии в ЕС и НАТО состоит в том, что она носит в большей мере евро-атлантический, чем сугубо европейский характер» [Воротников 2014: 15].

Стремясь обеспечить особые отношения с Брюсселем и Вашингтоном и заручиться их безоговорочной поддержкой, малые страны Балтии активно эксплуатируют тему так называемой растущей военной угрозы со стороны России. 
После событий на Украине и присоединения Крыма все три государства неоднократно отмечали появление «новых дестабилизирующих факторов», «рост непредсказуемости международной обстановки». В том числе исходя из таких оценок, они приняли новые концепции национальной безопасности: 26 ноября 2015 г. сейм утвердил Концепцию национальной безопасности Латвии, в мае 2017 г. была представлена на рассмотрение парламента новая редакция Концепции национальной безопасности Эстонии, а 17 января 2018 г. была одобрена парламентом Стратегия национальной безопасности Литвы.

В каждом из вышеперечисленных документов содержится объемный материал антироссийской направленности, призванный убедить читателя в наличии значительной угрозы, исходящей от России. Так, в Стратегии национальной безопасности Литвы основной проблемой ее безопасности называется «конвенциональная военная угроза, вызванная способностью и волей Российской Федерации использовать военную силу для достижения своих целей, сосредоточение и развитие ее военных мощностей по соседству с Литвой, а также военные мероприятия, лишенные прозрачности и демонстрирующие силу у границ Литовской республики и других стран - членов НАТО»1.

Определенное влияние на формирование национальной политики в области безопасности прибалтийских государств оказывают их специальные службы, в т.ч. внешняя разведка, деятельность которой полностью контролируется и направляется руководством НАТО через Комитет по делам разведки Альянса. В периодически публикуемых в государственных печатных изданиях прибалтийских государств открытых докладах на эту тему прослеживается откровенное повторение, если не сказать копирование, основных постулатов ведущих стран НАТО, и прежде всего Соединенных Штатов. Соответственно, стержневой темой открытых докладов и редких выступлений в местной прессе представителей прибалтийских спецслужб является «российская угроза» с элементом национального колорита.

Показателен в этом плане опубликованный весной 2018 г. Службой внешней разведки Эстонии (Valisluureamet) третий по счету открытый доклад «Международная безопасность Эстонии» 2 , большая часть которого (52 из 70 страниц) отведена анализу внутренней и внешней политики России в контексте проблем национальной безопасности Эстонии.

В пространном предисловии к докладу генеральный директор Службы Микк Марран фактически пытается выстроить зависимость между внешней политикой, проводимой Российской Федерацией, и безопасностью всего Европейского континента, включая, разумеется, и безопасность своей страны. При этом обращает на себя внимание по-школярски повторяемый ставший уже рутинным набор обвинений в адрес Москвы, давно подготовленный старшими партнерами Эстонии по НАТО. Очевидно заимствование этих стереотипов, в частности, и из Стратегии национальной безопасности США 2017. Это «попытки России нанести ущерб единству и доверию европейских наций», это «продолжение Россией политики, направленной на размыв западных ценностей», это «широкий фронт вмешательства России в дела других государств» и Т.Д.

В характерной для всех прибалтийских государств манере в отчете содержится целый ряд совершенно абсурдных и ничем не обоснованных утверждений,

\footnotetext{
${ }^{1}$ National Security Strategy of the Republic of Lithuania. - Ministry of National Defense of Lithuania official website. 2017. Доступ: https://kam.lt/en/defence_policy_1053/important_documents/strategical_documents. html (проверено 15.07.2018).

2 International Security and Estonia. Estonian Foreign Intelligence Service. 2018. Доступ: https://www. valisluureamet.ee/pdf/raport-2018-ENG-web.pdf (проверено 15.07.2018).
} 
которые, по мнению экспертов эстонской разведки, характеризуют внешнюю политику Российской Федерации. Так, российские корпорации «Газпром» и «Роснефть» представлены в качестве «мощного инструмента российской внешней политики», а в пассаже о внутренней обстановке в нашей стране авторы доклада высказывают предупреждения в адрес иностранных граждан об угрозе их безопасности в период пребывания на территории России и прямо рекомендуют отказаться от планов ее посещения.

Признавая, что «военное нападение России на государства НАТО в 2018 году маловероятно», авторы доклада тем не менее подчеркивают, что такие «акции» России, как военные учения вблизи границ прибалтийских государств «Запад 2017», следует рассматривать как «подготовку Россией полномасштабных военных действий против государств НАТО».

Несмотря на постоянное педалирование темы о российской угрозе и попытки стран Балтии внести свою лепту в дело обеспечения коллективной безопасности, в т.ч. посредством участия в международных миссиях, в последнее время Брюссель и Вашингтон менее охотно оказывают им необходимую помощь в этой сфере. Еще в ходе предвыборной президентской гонки Д. Трамп неоднократно отмечал, что НАТО слишком дорого обходится США и что необходимо пересмотреть объем расходов членов Альянса на общую оборону. В ходе выступления в штаб-квартире Центрального командования вооруженных сил США 6 февраля 2017 г. он заявил: «Мы всецело поддерживаем НАТО. Мы только просим, чтобы все члены НАТО вносили свою полную и справедливую долю в финансирование деятельности Североатлантического альянса, чего многие из них не делают. Многие из них даже не были близки к этому. Им придется это сделать» ${ }^{1}$.

Как малые государства - члены НАТО страны Балтии сталкиваются с типичными для таких государств проблемами небольшой численности их армий, недостаточного оснащения современной военной техникой, дефицита квалифицированных военных кадров, ограниченных возможностей расходов на оборону. Тем не менее руководства всех трех республик явно пытаются продемонстрировать личный вклад в дело обеспечения коллективной безопасности, в первую очередь посредством увеличения расходов на оборону и достижения ими необходимых по стандартам НАТО 2\% ВВП каждой из республик.

Такие намерения прописаны в Концепциях национальной безопасности Латвии, Литвы и Эстонии. Однако на сегодняшний день из трех малых прибалтийских государств только Эстония достигла этого показателя.

Таблица 1

\section{Расходы на оборону, в \% от ВВП}

\begin{tabular}{|c|c|c|c|c|}
\hline Страна/год & $\mathbf{2 0 1 4}$ & $\mathbf{2 0 1 5}$ & $\mathbf{2 0 1 6}$ & $\mathbf{2 0 1 7}$ \\
\hline Латвия & 0,93 & 1,04 & 1,46 & 1,75 \\
\hline Литва & 0,88 & 1,14 & 1,49 & 1,73 \\
\hline Эстония & 1,96 & 2,05 & 2,13 & 2,08 \\
\hline
\end{tabular}

Источник: Defense Expenditure of NATO Countries (2010-2017). Press release. March 15, 2018. URL: https://www.nato.int/nato_static_fl2014/assets/pdf/pdf_2018_03/20180315_180315-pr2018-16-en.pdf (accessed 15.07.2018)/

1 Jenkins A. Read President Trump's Speech Claiming the Press Doesn't Report Terror. - Time. February 6 , 2017. URL: http://time.com/4661658/donald-trump-terror-attacks-speech-macdill-air-force-base/ (accessed 15.07.2018). 
Сознавая свой небольшой потенциал в деле обеспечения коллективной безопасности Альянса, страны Балтии стремятся занять свою нишу в решении этой задачи и выбирают особую, узкую зону своей специализации. Латвия, Литва и Эстония принимают активное участие в формировании центров передового опыта (Centres of Excellence) НАТО - структур, предназначенных для подготовки и обучения руководителей и экспертов НАТО в различных областях. Так, Эстония, подвергшаяся массированным кибератакам в мае 2007 г., впоследствии стала одним из лидеров в создании системы предоставления государственных услуг в электронной форме и обеспечении кибербезопасности не только в рамках ЕС, но и в более широком контексте. С 2008 г. в Таллине действует Центр передового опыта НАТО в области кибербезопасности. Аналогичные центры по энергетической безопасности и стратегической коммуникации функционируют на территории Вильнюса (с 2013 г.) и Риги (с 2015 г.).

Для всех трех государств характерна широкая трактовка безопасности, в которую, помимо военной безопасности, входят экономическая, энергетическая, информационная и кибербезопасность, а также разграничение конвенциональных (военных) угроз и гибридных (невоенных). Несмотря на общность подходов к определению угроз, можно выделить и некоторые национальные особенности. Например, для Латвии, чья экономика сильнее всего пострадала в ходе кризиса, особую актуальность приобретает проблема построения эффективной и стабильной экономической среды, для Литвы ввиду ее высокой зависимости от поставок нефти и газа - энергетическая безопасность, для Эстонии - кибербезопасность. Как правило, наличие проблемной области влечет за собой создание отдельной стратегии по преодолению существующих угроз. Так, в Эстонии существует отдельный документ, посвященный проблемам кибербезопасности - Стратегия кибербезопасности Эстонии 2014-20171. Стратегия освещает важные недавние достижения в этой сфере, оценивает угрозы кибербезопасности Эстонии и содержит перечень мероприятий для борьбы с этими угрозами. В свою очередь, сейм Литвы 21 июня 2018 г. утвердил новую Национальную стратегию энергетической независимости. Стратегия предусматривает упрочение энергетической безопасности страны посредством интеграции национальных энергетических систем и рынков в европейские. Для этого предполагается реализация двух проектов: запуск до 2021 г. газопровода между Литвой и Польшей (GIPL), который диверсифицирует пути поставки в регионе, а также отключение от российских электросетей и соединение с сетями континентальной Европы к 2025 г. Кроме того, достижению энергетической безопасности будет способствовать сокращение зависимости страны от импорта электроэнергии. Планируется, что импорт будет постепенно заменен местным производством: к 2020 г. производство электроэнергии достигнет $35 \%$ общего потребления, в $2030-70 \%$, а в 2050 г. Литва будет полностью перейдет на самообеспечение.

В попытках преодолеть ограниченность собственных ресурсов Латвия, Литва и Эстония выступают за активное вовлечение гражданского общества в обеспечение национальной обороны. Показательно в этом плане заявление министра обороны Латвии Раймондса Бергманиса, который 5 апреля 2017 г. в ходе дискуссий в Комиссии сейма по вопросам обороны, внутренних дел и коррупции призвал «сменить парадигму национальной обороны и перейти от идеи, что боец - это только солдат с оружием в руках и поддержкой союзников, к убеждению, что каждый патриот своей страны может внести неоцени-

\footnotetext{
${ }^{1}$ Cyber Security Strategy 2014 - 2017. - Ministry of Economic Affairs and Communication. 2014. URL: https://www.mkm.ee/sites/default/files/cyber_security_strategy_2014-2017_public_version.pdf (accessed 15.07.2018).
} 
мый вклад в национальную оборону» ${ }^{1}$. Схожую точку зрения высказал и премьер-министр Эстонии Юри Ратас во время представления основ политики безопасности Эстонии в Рийгикогу 2 мая 2017 г.: «Безопасность - это не одни лишь бронемашины, форма и сапоги, на атмосферу безопасности сегодняшнего дня влияют не только танки и самолеты, но и киберпространство, перебои с электроснабжением, голод и нехватка воды. Строительство системы противодействия таким рискам требует вклада каждого из нас, сотрудничества всего общества» 2 .

Однако, несмотря на то что все три страны поддерживают идею привлечения населения к обеспечению безопасности, в их подходах к этому вопросу существуют некоторые различия. Как отмечают в своей статье политологи Марта Кепе и Ян Осбург, Эстония предполагает участие всех слоев общества, включая государственные институты, частный сектор и гражданские организации, в сохранении независимости и суверенитета страны [Kepe, Osburg 2017]. При таком подходе устойчивое и сплоченное общество выступает в роли «цементирующего материала», который соединяет оборону, безопасность, и внешнюю политику, а также обеспечивает доступность людских ресурсов и их готовность к активному ответу в случае необходимости: «В случае нападения Эстония будет защищать всю свою территорию от государственной границы и далее и оказывать военное сопротивление даже в районах, над которыми она может временно потерять контроль. Военный, экономический и другой потенциал Эстонии в целом будет использоваться для защиты страны. Участие всего общества в обороне и контратаке в максимальной степени обеспечивается высокой степенью готовности населения к защите своей страны, широкомасштабной военной подготовкой и большим числом участников Лиги обороны» 3 .

В Латвии основной упор делается на «устойчивость», под которой понимается «повышение способности противостоять гибридным угрозам, которые могут носить экономический, политический и технологический характер, противодействовать информационной войне и, как в случае Эстонии, усиливать социальную сплоченность» [Kepe, Osburg 2017]. Подход Литвы к национальной обороне предполагает мобилизацию всех национальных ресурсов для разгрома захватчика наряду с активным гражданским сопротивлением, которое является законным в соответствии с международным правом. Литва также использует концепцию «всеобъемлющей безопасности», которая предусматривает сотрудничество военных и гражданских институтов, объединение военного и гражданского потенциалов.

Очевидно, что система обеспечения национальной безопасности малых прибалтийских государств, в т.ч. как элемент самоидентичности, будет оставаться предметом внимания их руководства и широкой общественности. При этом не вызывает сомнения также и то обстоятельство, что в стратегическом плане курс на укрепление основ безопасности будет в основном определяться установками, формулируемыми в Брюсселе и Вашингтоне. Прежде всего это касается военной составляющей безопасности, в значительной части определяемой отношениями ведущих государств НАТО и США с Россией. Судя по очередному

\footnotetext{
1 Valsts aizsardzības mācība vidusskolās varētu būt viens no obligātajiem izvēles priekšmetiem. 2017 gada, 6. Aprīlis. Доступ: http://www.sargs.lv//lv/Zinas/Latvija/2017/04/06-01.aspx\#lastcomment (проверено 15.07.2018).

2 Премьер Эстонии назвал Россию одной из главных угроз безопасности. - Медийный портал Рамблер. Доступ: https://news.rambler.ru/baltic/36776247-premer-estonii-nazval-rossiyu-odnoy-iz-glavnyhugroz-bezopasnosti/ (проверено 15.07.2018).

3 National Security Concept of Estonia. Chapter 3.2. - Ministry of Defense of Estonia official website. Доступ: http://www.kaitseministeerium.ee/en/objectives-activities/basic-national-defence-documents (проверено 15.07.2018).
} 
«сенсационному» заявлению президента Литвы Дали Грибаускайте в интервью немецкому журналу Spiegel, что опасность вторжения Российской Федерации в Литовскую Республику «велика» ${ }^{1}$, в ближайшей перспективе руководство малых прибалтийских государств не намерено вносить какие-либо принципиальные изменения в свои отношения с восточным соседом.

Вместе с тем в процессе формирования системы национальной безопасности малых прибалтийских государств все более отчетливо проявляется дисбаланс между реальной ситуацией в сфере угроз национальной безопасности и ее интерпретацией в официальных документах и подконтрольных правительству СМИ. В условиях достаточно сложного и во многом непредсказуемого периода развития Евросоюза - многолетнего донора прибалтийских государств, а также с учетом недвусмысленных намерений администрации президента Дональда Трампа «внести коррективы» в экономические и военные отношения с Европой и определенных признаков ослабления жесткой конфронтации между Москвой и Вашингтоном тема национальной безопасности, особенно в контексте нагнетания в республиках антироссийских настроений, становится удобным инструментом, с помощью которого, с одной стороны, по замыслу прибалтийских идеологов, консолидируется национальное самосознание, а с другой - отвлекается внимание от решения жизненно важных проблем развития (экономика, энергетика, сокращение численности трудоспособного населения и т.д.).

\section{Список литературы}

Бразаускас А. 2002. Пять лет президента: События, воспоминания, мысли. М.: Унипринт. 624 с.

Воротников В.В. 2014. Страны Балтии в НАТО: итоги десятилетия. - Вестник МГИМО Университета. № 6(39). С. 9-17.

Смирнов В.А. 2017. Участие стран Прибалтики в политике санкций Евросоюза в отношении России: теоретические аспекты. - Известия Иркутского государственного университета. Сер. Политология. Религиоведение. Т. 21. С. 56-61.

Almost NATO: Partners and Players in Central and Eastern European Security (ed. by Ch. Krupnick). 2003. Lanham: Rowman \& Littlefield. 341 p.

Apprenticeship, Partnership, Membership: Twenty Years of Defense Development in the Baltic States (ed. by T. Lawrence, T. Jermalavičius) 2013. Tallinn. 282 p.

Kepe M., Osburg J. 2017. Total Defense: How the Baltic States Are Integrating Citizenry Into Their National Security Strategies. - Small Wars Journal. October, 20. URL: http://www.css.ethz.ch/en/services/digital-library/articles/article. html/354d2f22-8025-4065-b540-0a7d80535e84/pdf (accessed 15.07.2018).

Miniotaite G. 1999. The Security Policy of Lithuania and the 〈Integration Dilemma〉. Vilnus: Lithuanian Institute of Philosophy and Sociology. 38 p. URL: https://www. nato.int/acad/fellow/97-99/miniotaite.pdf (accessed 15.07.2018).

Möller F. 2007. Thinking Peaceful Change: Baltic Security Policies and Security Community Building. Syracuse, New York: Syracuse University Press. 379 p.

Urbelis V. 2003. Defense Policies of the Baltic States: from the Concept of Neutrality towards NATO Membership. NATO-EAPC Individual Fellowship Report. 2001-2003. Vilnus. 25 p. URL: https://www.nato.int/acad/fellow/01-03/vaidotas.pdf (accessed 15.07.2018).

\footnotetext{
1 Лангер А. Президент Литвы: «Молодое поколение готово защищать нашу страну». - Интернетпроект ИноСМИ.RU. 20.06.2018 г. Доступ: https://inosmi.ru/politic/20180620/242544001.html (проверено 15.07.2018).
} 
GRIBIN Nikolai Petrovich, Dr.Sci. (Legal), Professor; Director of the Centre for European Studies, Institute for International Studies, Moscow State Institute of International Relations, University of the Ministry for Foreign Affairs of Russia (76 Vernadskogo Ave, Moscow, Russia, 119454; n.gordin40@gmail.com)

YAKUTOVA UI'yana Vyacheslavovna, Laboratory Researcher at the Center for European Studies, Institute for International Studies, Moscow State Institute of International Relations, University of the Ministry for Foreign Affairs of Russia (76 Vernadskogo Ave, Moscow, Russia, 119454; uliana.postnikova@gmail.com)

\section{FEATURES OF FORMATION OF NATIONAL SECURITY SYSTEM OF SMALL BALTIC STATES}

Abstract. The article analyzes peculiarities of conceptualization of national security process in Latvia, Lithuania and Estonia after becoming independent in 1991. It demonstrates the evolution of approaches towards national security from maintaining neutrality and maximum independence to recognizing NATO as a cornerstone for national security and using so-called Russian threat in order to consolidate the society. Special attention the authors pay to analyzing the key national security documents and revealing general trends and differences in national security problems definition and resolution.

Keywords: national security, national security strategy, national security concept, cybersecurity, energy security, national identity, Baltic States

МЕДУШЕВСКИЙ Николай Андреевич - кандидат политических наук, доцент кафедры культуры мира и демократии ЮНЕСКО Российского государственного гуманитарного университета (125047, Россия, г. Москва, Миусская пл., 6; Luсky5659@yandex.ru)

\section{РАЗВИТИЕ ЭНЕРГЕТИЧЕСКОЙ СИСТЕМЫ ЕС КАК ВЫЗОВ УСТОЙЧИВОМУ РАЗВИТИЮ РЕГИОНА}

Аннотация. Энергетическая политика является одним из основных элементов комплексного развития Европейского союза. Ее оптимизация призвана диверсифицировать источники энергии, сделать ЕС максимально независимым от внешних энергетических поставок и демократизировать рынок энергетических ресурсов, позволив участвовать в выработке и торговле энергией рядовым европейцам. Тем не менее развитие европейской энергетической системы не может реализовываться изолированно от остального мира, т.к. внутренних ресурсов по выработке энергии в ЕС недостаточно. Решение этой проблемы в краткосрочной перспективе должно быть достигнуто через заключение контрактов на поставку энергоресурсов с такими странами, как Россия и Иран, однако в контексте геополитического противостояния данных государств с США сотрудничество с ними Европейского союза, в т.ч. отдельных стран $E C$, оказывается затрудненным, что создает явный вызов устойчивому европейскому развитию.

Ключевые слова: энергетика, риски, устойчивое развитие, “Северный поток», Парижское соглашение по климату, диверсификация поставок, безопасность

По данным международного экономического форума в 2017-2018 гг., Европейский союз столкнулся с 5 основными рисками глобального развития, в числе которых аналитики обозначили безработицу, миграцию, финансовый кризис, разрушение финансовых институтов и перекредитование, и продолжает им противостоять ${ }^{1}$. По мнению экспертов, преодоление данных

1 Shareable Infographics. Global Risks Report 2017. World Economic Forum. URL: http://reports. weforum.org/global-risks-2017/shareable-infographics/ 